\title{
Experimental and numerical investigations on optimal phase change material melting temperature utilized either alone or with night ventilation
}

\author{
Ebrahim Solgi ${ }^{1}$, Ruwan Fernando ${ }^{1}$, Zahra Hamedani ${ }^{1}$ \\ ${ }^{1}$ Griffith University, Gold Coast, Australia
}

\begin{abstract}
Phase change materials (PCMs) are a passive way of providing temperature amelioration without significant alteration to the building's design. As with many passive technologies, the use of PCMs is highly context-driven, with many non-linear relationships in the way the environmental system is affected. These include insulation, ventilation and the properties of the PCM itself, such as melting temperature and thickness. To explore the relationships between the different parameters, an exhaustive list of construction scenarios was created, making use of automation for generation and simulation. The simulation model was validated using a full-scale construction tested in a calorimeter. Automated methods were used to analyse and visualize the data that resulted from the large simulation set. The results demonstrate that although the presence of night ventilation (NV) will raise the PCM's efficiency, it has no effect on the optimum PCM melting temperature. Also, in tropical climates, the use of PCMs is not recommended, while NV alone is effective for sufficiently-insulated buildings.
\end{abstract}

\section{Introduction}

Passive techniques are of paramount importance in the building industry since their utilization can reduce building energy consumption and consequently the dependence on mechanical HVAC equipment (Fazlikhani, Goudarzi, \& Solgi, 2017). Passive systems are of particular significance in that the highest percentage of energy demand in buildings is for heating, cooling and ventilation (Pérez-Lombard, Ortiz, \& Pout, 2008). Having a range of $20-60 \%$ effect on the total energy demand, the building envelope is one of the most vital sections to address when attempting to reduce the energy used in buildings (Sadineni, Madala, \& Boehm, 2011). Therefore, the use of passive strategies such as Thermal Energy Storage (TES) which can lessen the HVAC system loads is of interest. TES system selection is chiefly contingent upon factors including the building's operating conditions, the diurnal or seasonal storage period required, and economic viability (Dincer, 2002).

PCMs are a popular type of TES material that use latent heat thermal storage to raise the overall heat capacity of buildings. Due to their high energy storage density as well as their efficiency in charging and discharging heat, PCMs have been utilized in many passive designs. The use of PCMs can considerably reduce the indoor air temperature fluctuations, causing a reduction in the energy consumption of buildings (Mandilaras, Stamatiadou, Katsourinis, Zannis, \& Founti, 2013; Nghana \& Tariku, 2016). Change of state is the main reason for PCM efficacy, since for absorbing and releasing energy, their state alters from solid to liquid or vice versa (Souayfane, Fardoun, \& Biwole, 2016). However, low thermal conductivity is the main downside of PCMs as this slows down their charging and discharging process and consequently their performance (Shah, 2018; E Solgi, 2014).

Thermal inertia is one of the building parameters influencing the performance of NV (Landsman, Brager, \& Doctor-Pingel, 2018; Ebrahim Solgi, Hamedani, Fernando, Skates, \& Orji, 2018). Thus, the use of PCMs as an efficient lightweight TES in buildings with night cooling systems has become prevalent (Ebrahim Solgi, Fayaz, \& Kari, 2016). NV is a passive cooling technique that utilizes natural ventilation at night in order to purge the excess heat and cool down structural elements such as suspended ceilings (Lança, Coelho, \& Viegas, 2019). As such, in addition to the economic viability of using PCMs (Ebrahim Solgi, Memarian, \& Moud, 2018), the implementation of PCMs into $\mathrm{NV}$ systems can considerably improve indoor thermal conditions (Ebrahim Solgi, Kari, Fayaz, \& Taheri, 2017).

Field studies, experimental studies and computer simulations have been utilized successfully to further research nocturnal ventilation, thermal mass and PCMs in buildings. Energy simulation software has been adapted to improve our understanding of theory based on the information from experiments and field results. Simulations are most useful, as they offer the possibility of testing different alternatives which would otherwise be difficult, time-consuming and costly to study under real conditions.

There are some studies regarding the optimal PCM melting temperatures when they are employed alone or in conjunction with NV systems. However, it is still unknown whether PCM parameters used alone or coupled with NV differ, and how thermal insulation affects these parameters. This research, used a validated experimental model and numerical simulations to explore optimal PCM melting temperatures under the aforementioned conditions in three different Australian climatic zones.

\section{Methods}

The model in this research is a full-scale calorimeter which has been used to study PCM behaviour (Ebrahim 
Solgi, Hamedani, Fernando, Kari, \& Skates, 2018). The calorimeter has dimensions of $210 \times 210 \times 90 \mathrm{~cm}$ with 30 $\mathrm{cm}$ of insulation, in addition to a north-facing test wall with dimensions of $150 \times 150 \mathrm{~cm}$. The test wall, containing BioPCM $-24^{\circ} \mathrm{C}$, is located inside the frame. Inside the model, there is a baffle with nine series $\mathrm{T}$ thermocouples, which have an error limit of $\pm 0.5{ }^{\circ} \mathrm{C}$, to measure the indoor temperature (see Figure 1, 2). Furthermore, in order to record the weather data during the experiment, a pyranometer (series Kipp \& Zonen CMP 3) with sensitivity of 5 to $20 \mu \mathrm{V} / \mathrm{W} / \mathrm{m}^{2}$, as well as a humidity and temperature logger have been utilized. All the obtained data were recorded at five minute intervals. A full description of the envelope structure, as well as the arrangement of the building materials in the experimental model and its validation can be found in (Ebrahim Solgi, Hamedani, Fernando, Kari, et al., 2018).

The calorimeter with all the characteristics outlined above as well as the incorporated BioPCM with melting temperature of $24^{\circ} \mathrm{C}$ were simulated in EnergyPlus. It is significant to note that BioPCMs consist of non-toxic fatty acids sourced from organic materials (Kosny, Kossecka, Brzezinski, Tleoubaev, \& Yarbrough, 2012).

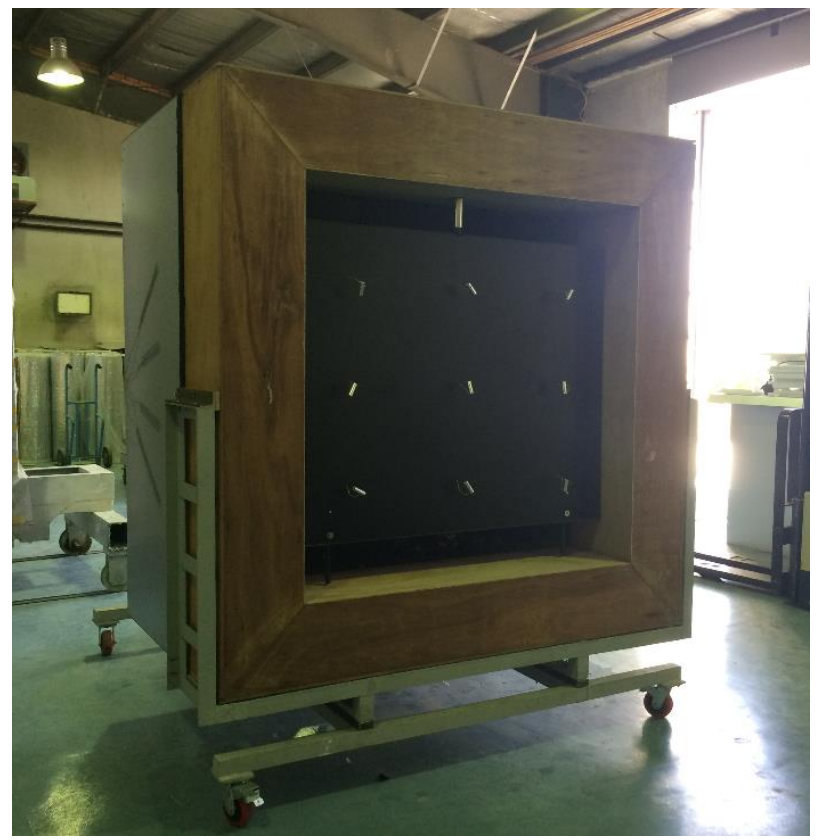

Figure 1: A schematic view of the calorimeter before installing the test wall (baffle and thermocouples).

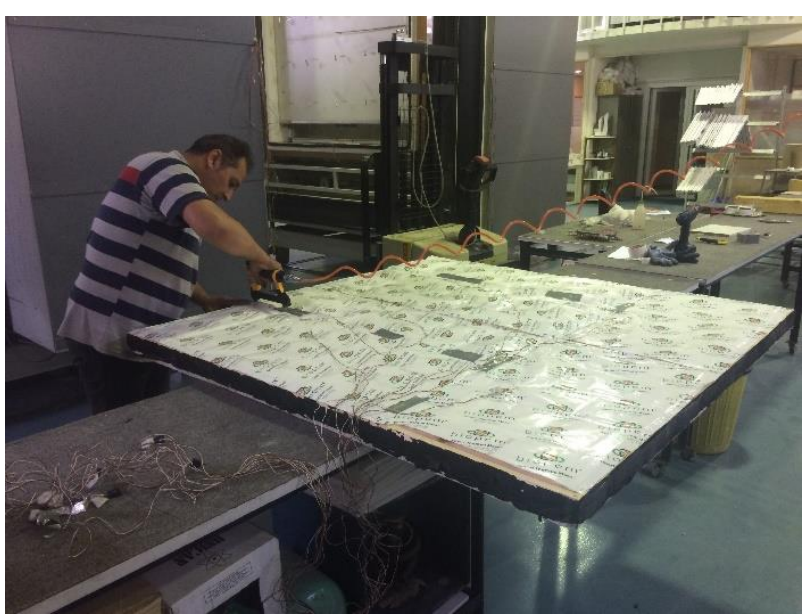

Figure 2: Installing PCMs on the test wall before incorporation into the calorimeter

This research was carried out using EnergyPlus version 8.7. EnergyPlus is a software application that simulates building energy consumption, described through input files containing a detailed model of building construction, HVAC systems and their controls. In order to substantiate the simulation conditions being similar to real building conditions, this software considers the conditions all through a secondary HVAC system and coil loads, the required heating and cooling load to satisfy defined setpoints for thermal comfort, the equipment energy consumption, and other requirements (Crawley, Lawrie, Pedersen, \& Winkelmann, 2000). EnergyPlus was selected for this project owing to its availability along with its capability for modelling natural ventilation and PCMs factors which are taken into account when calculating and modelling the energy performance. As the energy analysis field requires novel materials, such as PCMs, the Conduction Transfer Function (CTF) cannot be used with the material's thermal properties since it cannot be updated at every time step. Instead, a Conduction Finite Difference (CondFD) algorithm was added to simulate PCM behaviour or changeable thermal conductivity (Tabares-Velasco, Christensen, \& Bianchi, 2012).

The average difference between the indoor temperatures recorded with calorimeter and simulations within 10 days is around $2 \%$ with 0.95 coefficient correlation (See Figure $3)$. Due to the acceptable agreement between the experiment and simulations the calorimeter was used as a validated model for running annual cooling load. It is important to note that the thermostat heating and cooling set-points $\left(18^{\circ} \mathrm{C}\right.$ and $26^{\circ} \mathrm{C}$, respectively) were based on the Australian National Construction Codes, and were applied to the model which has an office schedule of 8 am to $5 \mathrm{pm}$. 


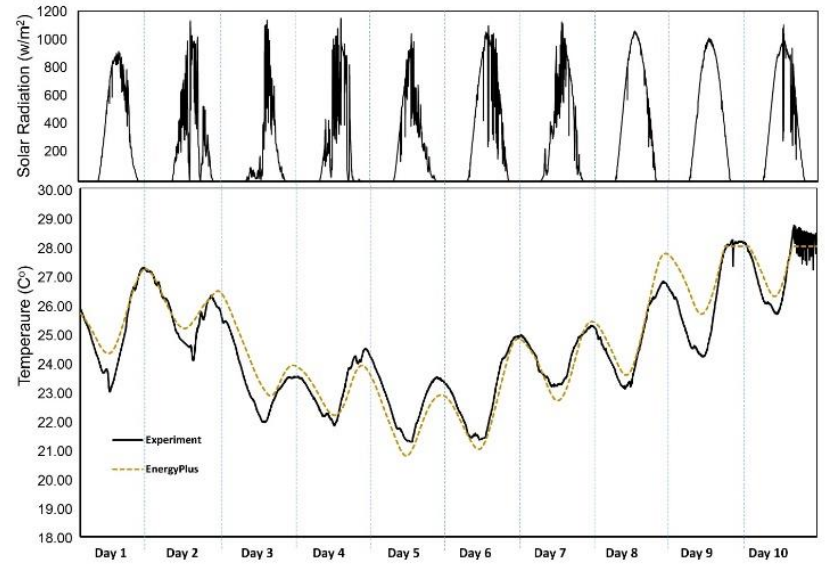

Figure 3: A comparison between experimentation and simulations over ten days (Ebrahim Solgi, Hamedani, Fernando, Kari, et al., 2018).

\section{Automation}

To run the simulations of this experiment series, a custom application was written, which worked in three parts. The first, was reading a base IDF file, which is the format used by EnergyPlus that describes the simulation parameters, including geometry, material properties and mechanical systems operation. The parser was created using the ANTLR platform. Having parsed in a text file and having it converted to programming objects, selected parameters were altered using a combinatorial sequence and for each parameter a separate IDF file created. Each of these was run through EnergyPlus across multiple computers. One situation that should be anticipated by others, using similar techniques, is that EnergyPlus does not allow for a 'zero' length material. Therefore, the IDF file generator has to deal with this case specifically, in order to verify the effect of the materials. Analysing the data also required custom scripting as reading through gigabytes of data could not be achieved manually. In this case, the total cooling and heating loads were extracted for the different climates. Based upon the Köppen and Geiger climate classification (Kottek, Grieser, Beck, Rudolf, \& Rubel, 2006), three Australian cities in different climatic zones, namely Alice Springs (hot-dry), Brisbane (sub-tropical), and Darwin (tropical) were considered for this study.

\section{Results and discussion}

Table 1 illustrates the effects of insulation, PCM thicknesses, and night ventilation on the optimal PCM melting temperature as well as cooling load reductions. Note that although the low and high delta temperatures and airflow rates can both augment the NV efficiency, they have no impact on the optimum PCM melting temperatures (Ebrahim Solgi, Hamedani, Fernando, Kari, et al., 2018). Thus, in this section, NV with the airflow rate of $5 \mathrm{ACH}$ along with the delta temperature of $1^{\circ} \mathrm{C}$ was performed.

As illustrated, in the Alice Springs hot-dry climate, in the case of using $40 \mathrm{~mm}(\mathrm{R}$-value $=1.08 \mathrm{Km} 2 / \mathrm{W})$ insulation and $10 \mathrm{~mm}$ PCM, the melting temperature of $26{ }^{\circ} \mathrm{C}$ was optimal for either using PCM alone or with NV; thus, this PCM could reduce cooling loads around 9 and 16\%, respectively. However, for the insulation thicknesses greater than $40 \mathrm{~mm}, \mathrm{PCM}-25^{\circ} \mathrm{C}$ was optimal. That is, for 80,120 , and $160 \mathrm{~mm}(\mathrm{R}$-values of $2.05,3.03$, and 4 $\mathrm{m}^{2} \mathrm{~K} / \mathrm{W}$ ) insulation, the amount of energy saving for utilizing PCMs was 3.5, 2.1, and $1.3 \%$, while for the PCMs coupled with NV the saving was 10.2, 8.4, and 7.1 $\%$, respectively. As can be seen, the productivity values, expected by energy savings from using insulation in both case scenarios are greater than the PCM thickness itself, and the reason for reducing the energy saving while increasing the envelope R-values is the noticeable drop in the base loads attributable to insulation implementation. Notably, all the presented percentages are relative to the base condition (without PCM). Interestingly, the trend for energy saving and the optimum PCM transitional temperatures when it is used in conjunction with $\mathrm{NV}$ systems are akin to using PCMs exclusively, whilst the amount of energy saving in the case of performing NV is higher. Moreover, by increasing the PCM thickness despite improved energy savings in both case scenarios (with and without NV), the optimal PCM melting temperatures remain constant. For instance, the average amount of energy saving in the case of using $30 \mathrm{~mm}$ PCMs with and without NV was approximately twice that of $10 \mathrm{~mm}$ PCMs, while the optimal melting points are the same.

For the Brisbane sub-tropical climate, the impact of envelope R-values and PCM thickness on the optimal PCM transitional temperature were the same as the previous climate, and for the R-values of $2.05 \mathrm{~m}^{2} \mathrm{~K} / \mathrm{W}$ and greater, $\mathrm{PCM}-25^{\circ} \mathrm{C}$ was optimal. However, in the case of employing $30 \mathrm{~mm}$ PCM coupled with NV, even for the Rvalues of $1.08 \mathrm{Km} 2 / \mathrm{W}$ the transitional temperature of $25^{\circ} \mathrm{C}$ was the optimum. The amount of cooling load in sub-tropical climates is less than hot-dry climates, but as the duration for which $\mathrm{NV}$ can be performed is higher, the impact of combining PCMs and NV is noticeable. For instance, the use of $30 \mathrm{~mm}$ PCMs along with NV could save an approximate average of $78 \%$ for all types of insulation as opposed to $19.8 \%$ for Alice Springs. Therefore, the conclusion is that although the PCM thickness and NV existence generally do not have any effect on the optimal PCM temperatures, the impact of insulation in reducing cooling loads is of paramount importance. In the climates outlined above and despite NV existence, for a sufficiently insulated building, the optimal PCM melting temperature, whether there is NV or not, is $1{ }^{\circ} \mathrm{C}$ lower than the cooling set-point (which is $26^{\circ} \mathrm{C}$ ). Furthermore, both climates, are NV-and-PCM efficient, and the use of NV will escalate the total energy saving. Furthermore, the impact of performing NV on saving energy was more notable that both thermal insulation and PCM application. For example, in Alice Springs, in the case of having $40 \mathrm{~mm}$ insulation, the use of NV or PCMs reduced cooling load approximately $45 \%$ and $14.2 \%$, whereas increasing the insulation thickness to $160 \mathrm{~mm}$ resulted in $22 \%$ reduction in cooling load. 
In the tropical climate of Darwin, in the case of using 40 $\mathrm{mm}$ insulation and $10 \mathrm{~mm}$ PCMs, the optimal transitional temperature was $27{ }^{\circ} \mathrm{C}$ (just using PCMs) and $25{ }^{\circ} \mathrm{C}$ (PCMs and NV), respectively. Similar to the previous climates, for the insulation thicknesses of greater than 40 $\mathrm{mm}, 25{ }^{\circ} \mathrm{C}$ was the best melting temperature. Nevertheless, the use of PCMs in conjunction with 120 and $160 \mathrm{~mm}$ insulation had a negative effect on energy saving and will increase the energy saving percentages by -0.3 to -0.76 and -0.65 to -1.7 , respectively. Also, for these insulation thicknesses, the impact of NV coupled with PCMs was nominal. Although the use of PCMs and NV coupled with low R-value envelopes can reduce energy consumption, these methods are not highly efficient in this climate. That is, in the best case scenario, providing that $30 \mathrm{~mm}$ PCMs and $40 \mathrm{~mm}$ insulation are being utilized, the energy saving can account for $19.4 \mathrm{MJ}$; and for the included $\mathrm{NV}$ it can account for $30 \mathrm{MJ}$, while by just increasing the insulation thickness, the energy demands would reduce to $47.6 \mathrm{MJ}$ and $43.2 \mathrm{MJ}$, respectively. This trend for a higher amount of insulation continues even when the PCMs are no longer efficient. Additionally, without using PCMs, just by employing NV as well as raising thermal insulation, the best results can be obtained, with the result that by using $160 \mathrm{~mm}$ insulation coupled with $\mathrm{NV}$, the cooling load will be almost one-third of $40 \mathrm{~mm}$ insulation without NV.

Table 1: The impact of insulation and PCM thickness on the optimum PCM melting temperature whether coupled with NV.

\begin{tabular}{|c|c|c|c|c|c|c|c|c|c|c|c|c|c|c|c|}
\hline \multicolumn{4}{|c|}{ PCM $25^{\circ} \mathrm{C}$} & \multicolumn{6}{|c|}{ PCM $26^{\circ} \mathrm{C}$} & \multicolumn{6}{|c|}{$\mathrm{PCM} 27^{\circ} \mathrm{C}$} \\
\hline \multirow{2}{*}{ Cities } & \multirow{2}{*}{$\begin{array}{c}\text { Insulation } \\
\text { Thickness } \\
\text { (mm) }\end{array}$} & \multirow{2}{*}{$\begin{array}{l}\text { No } \\
\text { PCM } \\
\text { (MJ) }\end{array}$} & \multirow{2}{*}{$\begin{array}{c}\text { NV } \\
\text { without } \\
\text { PCM }\end{array}$} & \multicolumn{2}{|c|}{$\begin{array}{c}10 \text { mm PCM } \\
(M J)\end{array}$} & \multicolumn{2}{|c|}{$\begin{array}{c}10 \text { mm PCM \& } \\
\text { NV(MJ) }\end{array}$} & \multicolumn{2}{|c|}{$\begin{array}{c}20 \text { mm PCM } \\
(\mathrm{MJ})\end{array}$} & \multicolumn{2}{|c|}{$\begin{array}{c}20 \text { mm PCM } \\
\& \text { NV(MJ) }\end{array}$} & \multicolumn{2}{|c|}{$\begin{array}{c}30 \mathrm{~mm} \text { PCM } \\
(\mathrm{MJ})\end{array}$} & \multicolumn{2}{|c|}{$\begin{array}{c}30 \text { mm PCM \& } \\
\text { NV(MJ) }\end{array}$} \\
\hline & & & & $\begin{array}{c}\text { CL } \\
(\mathbf{M J})\end{array}$ & $\begin{array}{c}\text { CLR } \\
\%\end{array}$ & $\begin{array}{c}\text { CL } \\
(\mathbf{M J})\end{array}$ & $\begin{array}{c}\text { CLR } \\
\%\end{array}$ & $\begin{array}{c}\text { CL } \\
(\mathbf{M J})\end{array}$ & $\begin{array}{c}\text { CLR } \\
\%\end{array}$ & $\begin{array}{c}\text { CL } \\
(\mathbf{M J})\end{array}$ & $\begin{array}{c}\text { CLR } \\
\%\end{array}$ & $\begin{array}{c}\text { CL } \\
(\mathbf{M J})\end{array}$ & $\begin{array}{c}\text { CLR } \\
\%\end{array}$ & $\begin{array}{c}\text { CL } \\
(\mathbf{M J})\end{array}$ & $\begin{array}{c}\text { CLR } \\
\%\end{array}$ \\
\hline \multirow{4}{*}{$\begin{array}{l}\text { Alice } \\
\text { Springs }\end{array}$} & 40 & 154.5 & 85.3 & 140.6 & 9 & 72.0 & 15.6 & 135.9 & 12 & 67.1 & 21.3 & 132.5 & 14.2 & 62.6 & 26.6 \\
\hline & 80 & 131.4 & 60.9 & 126.8 & 3.5 & 54.7 & 10.2 & 124.6 & 5.2 & 51.7 & 15.1 & 122.7 & 6.6 & 48.8 & 19.8 \\
\hline & 120 & 123.7 & 51.5 & 121 & 2.1 & 47.2 & 8.4 & 119.9 & 3 & 44.7 & 13.2 & 118.8 & 3.9 & 42.6 & 17.3 \\
\hline & 160 & 119.8 & 46.5 & 118.2 & 1.3 & 43.2 & 7.1 & 117.9 & 1.8 & 41.1 & 11.6 & 117 & 2.3 & 39.2 & 15.7 \\
\hline \multirow{4}{*}{ Brisbane } & 40 & 60.8 & 10.8 & 46.3 & 23.9 & 4.0 & 62.9 & 44.3 & 27.2 & 3.0 & 72.4 & 42.5 & 30.1 & 2.4 & 77.7 \\
\hline & 80 & 48.2 & 5.0 & 43.1 & 10.4 & 2.4 & 50.4 & 41.4 & 14 & 1.6 & 67.3 & 40 & 16.8 & 1.1 & 78.4 \\
\hline & 120 & 44.3 & 3.2 & 41.5 & 6.4 & 1.6 & 49.3 & 40.4 & 8.7 & 1.0 & 67.7 & 39.5 & 10.8 & 0.7 & 79.1 \\
\hline & 160 & 42.4 & 2.4 & 40.6 & 4.8 & 1.3 & 48.5 & 40 & 5.5 & 0.8 & 66.3 & 39.3 & 7.2 & 0.5 & 78.6 \\
\hline \multirow{4}{*}{ Darwin } & 40 & 315.6 & 176.4 & 305.6 & 3.1 & 159.2 & 9.7 & 301 & 4.6 & 153.7 & 12.9 & 296.2 & 6.2 & 149.4 & 15.3 \\
\hline & 80 & 268 & 133.2 & 267.2 & 0.3 & 128.4 & 3.6 & 266.4 & 0.6 & 126.3 & 5.2 & 265.6 & 0.9 & 124.8 & 6.3 \\
\hline & 120 & 249.5 & 116.1 & 250.4 & -0.3 & 114.1 & 1.8 & 251 & -0.6 & 113.7 & 1.8 & 251.5 & -0.76 & 113.6 & 2.2 \\
\hline & 160 & 239.6 & 106.7 & 241.2 & -0.65 & 106.2 & 0.4 & 242.5 & -1.2 & 106.2 & 0.4 & 243.6 & -1.7 & 106.1 & 0.5 \\
\hline
\end{tabular}

\section{CL: Cooling Load}

CLR: Cooling Load Reduction

\section{Conclusion}

In this study, a validated model using a full-scale calorimeter was utilized to determine the optimum PCM melting temperatures, whether PCM was used in conjunction with NV or not. For this exploration, through automating EnergyPlus software, a parametric study was carried out in three different Australian climatic zones.

The results of the study have shown that regardless of the presence of night ventilation:

- the optimal PCM melting temperatures is generally not dependent on the PCM thickness. That is, for lowinsulated opaque envelopes, the optimal PCM melting temperatures for cooling dominant climate are generally equal to the cooling set-point temperature;

- for all climates, thickening PCMs augments the total energy saving, and the saving proportion is contingent upon the climatic conditions;
- the use of well-insulated envelopes in sub-tropical and hot-dry climates both increases the PCM productivity and stabilizes the optimum PCM melting temperature, which is $1^{\circ} \mathrm{C}$ lower than the cooling set-point temperature;

- in tropical climates, although the use of low R-value envelopes can reduce the cooling load, for wellinsulated envelopes, the use of PCM is either pointless or has negative effect on overall energy consumption. However, utilizing NV alonne in a well-insulated building is more efficient than any added PCM scenarios.

\section{Acknowledgement}

This research was supported by the Griffith Cities Research Institute. We thank our colleagues from the Tehran Building and Housing Research Center who provided insight and expertise that greatly assisted the research. 


\section{References}

Crawley, D. B., Lawrie, L. K., Pedersen, C. O., \& Winkelmann, F. C. (2000). Energy plus: energy simulation program. ASHRAE journal, 42(4), 49-56.

Dincer, I. (2002). On thermal energy storage systems and applications in buildings. Energy and buildings, 34(4), 377-388.

Fazlikhani, F., Goudarzi, H., \& Solgi, E. (2017). Numerical analysis of the efficiency of earth to air heat exchange systems in cold and hot-arid climates. Energy Conversion and Management, 148, 78-89.

Kosny, J., Kossecka, E., Brzezinski, A., Tleoubaev, A., \& Yarbrough, D. (2012). Dynamic thermal performance analysis of fiber insulations containing bio-based phase change materials (PCMs). Energy and buildings, 52, 122-131.

Kottek, M., Grieser, J., Beck, C., Rudolf, B., \& Rubel, F. (2006). World map of the Köppen-Geiger climate classification updated. Meteorologische Zeitschrift, 15(3), 259-263.

Lança, M., Coelho, P. J., \& Viegas, J. (2019). Enhancement of heat transfer in office buildings during night cooling- reduced scale experimentation. Building and Environment, 148, 653-667.

Landsman, J., Brager, G., \& Doctor-Pingel, M. (2018). Performance, prediction, optimization, and user behavior of night ventilation. Energy and buildings, 166, 60-72.

Mandilaras, I., Stamatiadou, M., Katsourinis, D., Zannis, G., \& Founti, M. (2013). Experimental thermal characterization of a Mediterranean residential building with PCM gypsum board walls. Building and Environment, 61, 93-103.

Nghana, B., \& Tariku, F. (2016). Phase change material's (PCM) impacts on the energy performance and thermal comfort of buildings in a mild climate. Building and Environment, 99, 221-238.

Pérez-Lombard, L., Ortiz, J., \& Pout, C. (2008). A review on buildings energy consumption information. Energy and buildings, 40(3), 394-398.
Sadineni, S. B., Madala, S., \& Boehm, R. F. (2011). Passive building energy savings: A review of building envelope components. Renewable and Sustainable Energy Reviews, 15(8), 3617-3631.

Shah, K. W. (2018). A review on enhancement of phase change materials-A nanomaterials perspective. Energy and buildings.

Solgi, E. (2014). Optimizing Thermal Mass in Night Ventilation Master thesis. Faculty of Architecture and Urbanism, Art University.

Solgi, E., Fayaz, R., \& Kari, B. M. (2016). Cooling load reduction in office buildings of hot-arid climate, combining phase change materials and night purge ventilation. Renewable Energy, 85, 725-731.

Solgi, E., Hamedani, Z., Fernando, R., Kari, B. M., \& Skates, H. (2018). A parametric study of phase change material behaviour when used with night ventilation in different climatic zones. Building and Environment, 147, 327-336.

Solgi, E., Hamedani, Z., Fernando, R., Skates, H., \& Orji, N. E. (2018). A Literature Review of Night Ventilation Strategies in Buildings. Energy and buildings, 173, 337-352.

Solgi, E., Kari, B. M., Fayaz, R., \& Taheri, H. (2017). The impact of phase change materials assisted night purge ventilation on the indoor thermal conditions of office buildings in hot-arid climates. Energy and buildings, 150, 488-497.

Solgi, E., Memarian, S., \& Moud, G. N. (2018). Financial Viability of PCMs in Countries with Low Energy Cost: A Case Study of Different Climates in Iran. Energy and buildings, 173, 128-137.

Souayfane, F., Fardoun, F., \& Biwole, P.-H. (2016). Phase change materials (PCM) for cooling applications in buildings: A review. Energy and buildings, 129, 396-431.

Tabares-Velasco, P. C., Christensen, C., \& Bianchi, M. (2012). Verification and validation of EnergyPlus phase change material model for opaque wall assemblies. Building and Environment, 54, 186-196. 